\title{
The Effect of Birthrate Granularity on the Release-to-Birth Ratio for the AGR-1 In-Core Experiment
}

HTR 2012

D. M. Scates

J. B. Walter

J. T. Maki

J. W. Sterbentz

J. R. Parry

\section{October 2012}

U.S. Department of Energy

National Laboratory

operated by

Battelle Energy Alliance

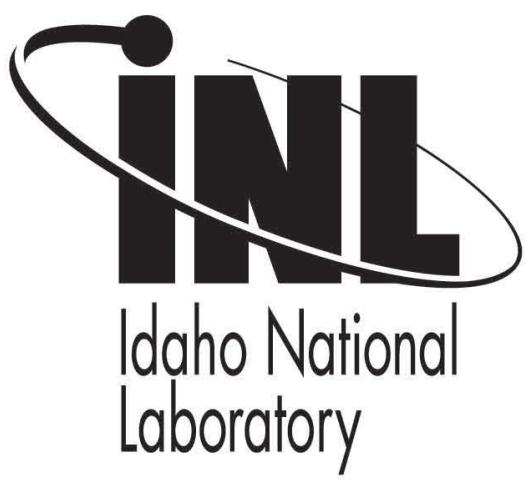

This is a preprint of a paper intended for publication in a journal or proceedings. Since changes may be made before publication, this preprint should not be cited or reproduced without permission of the author. This document was prepared as an account of work sponsored by an agency of the United States Government. Neither the United States Government nor any agency thereof, or any of their employees, makes any warranty, expressed or implied, or assumes any legal liability or responsibility for any third party's use, or the results of such use, of any information, apparatus, product or process disclosed in this report, or represents that its use by such third party would not infringe privately owned rights. The views expressed in this paper are not necessarily those of the United States Government or the sponsoring agency. 


\title{
The Effect of Birthrate Granularity on the Release-to-Birth Ratio for the AGR-1 In-Core Experiment
}

\author{
D. M. Scates, J. B. Walter ${ }^{\text {, }}$, J. T. Maki, J. W. Sterbentz, J. R. Parry \\ Idaho National Laboratory \\ 2525 N. Fremont Avenue, Idaho Falls, ID 83415, USA \\ phone: 1-208-526-5503,Dawn.Scates@inl.gov
}

\begin{abstract}
The AGR-1 Advanced Gas Reactor (AGR) tristructural-isotropic-particle fuel experiment underwent 13 irradiation intervals from December 2006 until November 2009 within the Idaho National Laboratory Advanced Test Reactor in support of the Next Generation Nuclear Power Plant program. During this multiyear experiment, release-to-birth rate ratios were computed at the end of each operating interval to provide information about fuel performance. Fission products released during irradiation were tracked daily by the Fission Product Monitoring System using 8-hour measurements. Birth rates calculated by MCNP with ORIGEN for as-run conditions were computed at the end of each irradiation interval. Each time step in MCNP provided neutron flux, reaction rates and AGR-1 compact composition, which were used to determine birth rates using ORIGEN. The initial birth-rate data, consisting of four values for each irradiation interval at the beginning, end, and two intermediate times, were interpolated to obtain values for each 8-hour activity. The problem with this method is that any daily changes in heat rates or perturbations, such as shim control movement or core/lobe power fluctuations, would not be reflected in the interpolated data and a true picture of the system would not be presented. At the conclusion of the AGR-1 experiment, great efforts were put forth to compute daily birthrates, which were reprocessed with the 8 -hour release activity. The results of this study are presented in this paper.
\end{abstract}

\section{INTRODUCTION}

The AGR-1 Advanced Gas Reactor (AGR) incore experiment was the first test in a series of planned tristructural isotropic (TRISO) coated particle fuel experiments irradiated within the Advanced Test Reactor (ATR) located at the Idaho National Laboratory (INL) Site. AGR-1 was inserted into the ATR in 2006 with initial irradiation commencing on December 24, 2006 and ending on November 6, 2009, after 620 effective full power days (EFPDs) of irradiation.

The intent of the AGR-1 experiment was to serve as a shakedown for a multicapsule test train using laboratory-scale fuel. Data from the original experiment was collected and analyzed over the course of the experiment to provide near real-time measurements. Part of this data generation consisted of calculating release-to-birth rate ratios $(\mathrm{R} / \mathrm{Bs})$ during irradiation cycle outages. These ratios were used to monitor the integrity of the fuel and give researchers a glimpse of fuel performance during the multiyear experiment. Initially, AGR-1 R/Bs were calculated using only four provided birthrates per each irradiation interval, which reflected births when the reactor reached full power, midway through the cycle, and before the end of cycle. Release rates computed from nuclide concentrations collected from the INL Fission Product Monitoring System (FPMS) were available every 8 hours and were processed through the FPMS post-processing software to determine daily ratios. The problem with this method is that any daily changes in heat rates or perturbations, such as outer shim control cylinder (OSCC), neck shim withdrawals, or core/lobe power fluctuations, would not be reflected in the interpolated data, and a true picture of the system would not be presented.

This paper summarizes the AGR-1 experiment and methods used to calculate the $\mathrm{R} / \mathrm{B}$ values. It also compares the use of daily birthrates with the four birthrates per irradiation interval. This study will 
hopefully enhance the understanding of monitoring for real-time fission product releases and provide a mechanism to support future fuel development.

\section{SUMMARY OF THE AGR - EXPERIMENT}

The AGR-1 experiment exclusively contained UCO type fuel. The test train of six individual test capsules was inserted into the B-10 position within the ATR as shown in Fig. 1. Each capsule consisted of 12 compacts supported within a graphite matrix [1], and each compact contained on average 4,150 fuel particles with total uranium content of 0.9 grams. All capsules were instrumented with thermocouples and were continuously swept with a custom blend of inert gas during irradiation [2]. The inert gas carried fission products downstream to the individual FPMS as shown in Fig. 2.

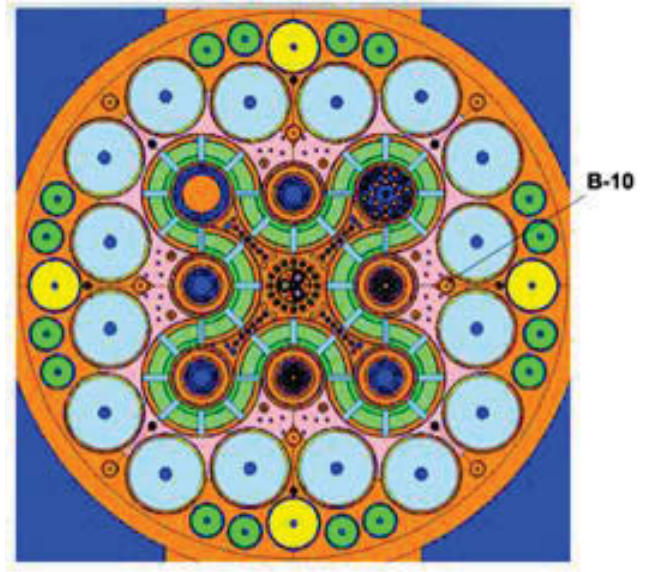

Fig. 1: A schematic of the Advanced Test Reactor located at the Idaho National Laboratory. The AGR-1 experiment was placed into the B-10 test facility at the ATR.

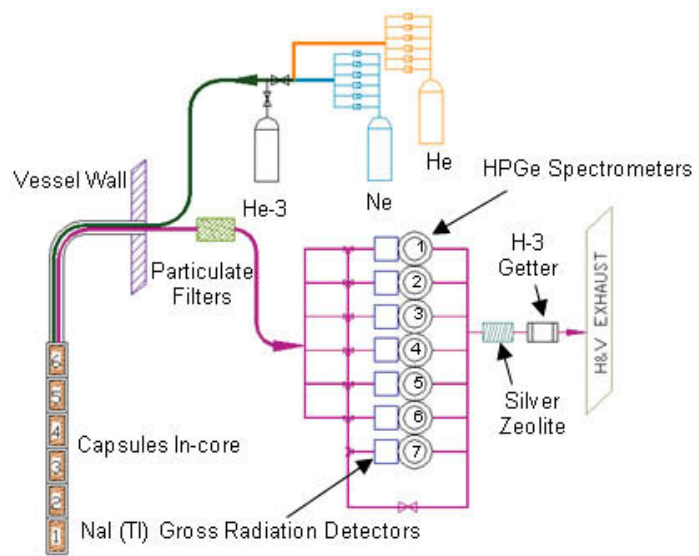

Fig. 2: Simplified gas flow path for the AGR-1 experiment.
The AGR-1 experiment was irradiated for a total of 620 EFPD and achieved a peak fuel burnup of $19.6 \%$ fissions per initial heavy metal atom (FIMA). No particle failures were observed during the total irradiation period, and only small amounts of disperssed uranium contamination were detected by the FPMS. Table 1 contains key irradiation conditions for the AGR-1 experiment [2].

\begin{tabular}{|c|c|c|c|}
\hline Capsule & $\begin{array}{c}\text { Peak } \\
\text { Burn Up } \\
(\% \text { FIMA) }\end{array}$ & $\begin{array}{c}\text { Peak fast } \\
\text { Fluence } \\
\left(10^{25} \mathrm{n} / \mathrm{m}^{2},\right. \\
\mathrm{E}>0.18 \mathrm{MeV})\end{array}$ & $\begin{array}{c}\text { Time } \\
\text { Average Peak } \\
\text { Temperature } \\
\left({ }^{\circ} \mathrm{C}\right)\end{array}$ \\
\hline 1 & 17.2 & 3.43 & 1162 \\
\hline 2 & 19.1 & 4.12 & 1238 \\
\hline 3 & 19.6 & 4.39 & 1211 \\
\hline 4 & 19.5 & 4.32 & 1254 \\
\hline 5 & 18.4 & 3.91 & 1231 \\
\hline 6 & 15.0 & 3.08 & 1183 \\
\hline
\end{tabular}

Table 1: Preliminary AGR-1 experiment results.

\section{DATA COLLECTION}

\section{III.A. Fission Product Monitoring}

The AGR-1 fission product monitor system (FPMS) is designed to control and monitor the operation of up to seven individual measurement stations that are continuously measuring the quantity of certain radioactive species present in the effluent gases released by test capsules being irradiated in ATR. Each station consists of a hyper-pure germanium (HPGe) spectrometer and a NaI detector. The HPGe detector is used to monitor and quantify the fission isotopes released from the test capsules and present in the effluent gases flowing through a $58 \pm 3 \mathrm{~mL}$ sample chamber. The NaI detector is used to monitor the gross counting rate from the effluent gas flowing through the lines before they reach the sample chamber. The digitized results from the HPGe and NaI detectors are histogrammed by an acquisition interface module and a multichannel analyzer. The accumulated data is transmitted to the host computer under the control of the FPMS software. The FPMS control program continually monitors the operation of each of the seven stations. The usual measurement protocol acquires gammaray spectra with counting times of 8 hours. This gives adequate measurement sensitivity and provides three sets of results each day, which are used to compute daily release activity values $[3,4]$. 


\section{III.B. Release Activity Computation}

The performance of a nuclear fuel test is typically evaluated using $\mathrm{R} / \mathrm{Bs}$ - the ratio of the released activity $(\mathrm{R})$ of an isotope from the fuel to the predicted creation rate of the isotope because of irradiation conditions (birth activity (B)). The gamma-ray spectrum measurements from the HPGe detectors in each FPMS were used to find the release activities of several different isotopes of krypton and xenon shown in Table 2. The acquired spectra were automatically analyzed using the INL-developed PCGAP gamma-ray spectral analysis code $[5,6]$ and were stored electronically. At the end of each irradiation cycle the FPMS measured activities were corrected to account for decay that occurred during transport from the capsules to the detectors. Transport times were calculated from outlet gas flow rates recorded by the automated experiment data control system of the ATR and the capsule-specific volumes through which samples flow to reach the respective monitoring stations [7].

\begin{tabular}{ccc}
\hline \multicolumn{3}{c}{ Isotope } \\
\hline $\mathrm{Kr}-85 \mathrm{~m}$ & $\mathrm{Xe}-131 \mathrm{~m}$ & $\mathrm{Xe}-135 \mathrm{~m}$ \\
$\mathrm{Kr}-87$ & $\mathrm{Xe}-133$ & $\mathrm{Xe}-137$ \\
$\mathrm{Kr}-88$ & $\mathrm{Xe}-135$ & $\mathrm{Xe}-138$ \\
$\mathrm{Kr}-89$ & & $\mathrm{Xe}-139$ \\
$\mathrm{Kr}-90$ & & \\
\hline
\end{tabular}

Table 2: The table above contains the isotopes of interest for release to birth calculations. Release activities were measured with the FPMS, and fission product birth rates were estimated using MCWO.

The activities measured from the spectra collected by the FPMS, corrected for decay during transport, were converted to released atoms per second at the capsule. The proper correction for the measured activity is calculated for equilibrium conditions for the different components illustrated in the simplified flow system in Fig. 3.

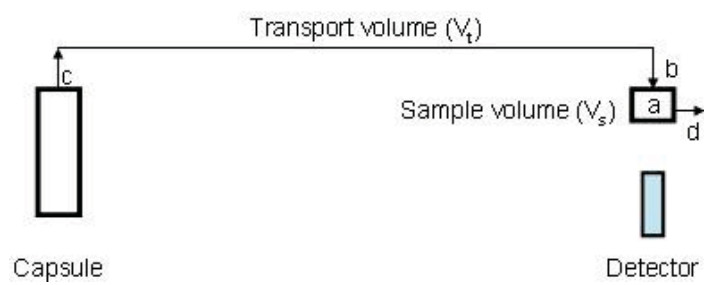

Fig. 3: A simplified single capsule flow graphic to aid in flow correction calculations.
At equilibrium, when the rate of change of the number of atoms of an isotope of interest in the sample volume, ' $a$,' is zero, one can derive

$$
R_{c}=\frac{A_{a} \cdot e^{\lambda \cdot V_{t} / \dot{f}}}{\left(1-e^{-\lambda \cdot V_{s} / \dot{f}}\right)}
$$

where:

$\mathrm{R}_{\mathrm{c}}=$ Release rate $($ atom $/ \mathrm{sec})$ of isotope at the capsule exit (c)

$A_{a}=$ Activity $(\mathrm{Bq})$ of isotope in sample volume $a$

$\lambda=$ Decay constant of isotope $\left(\mathrm{sec}^{-1}\right)$

$V_{T}=$ Transport volume $(\mathrm{mL})$ between $(c)$ and $(b)$

$V_{s}=$ Sample volume $(\mathrm{mL})(a)$

$f$ Capsule specific flow $(\mathrm{mL} / \mathrm{sec})$.

The flow rate is taken as the average of all values with times during the spectrum acquisition. The activities (A) provided by the INL-developed PCGAP analysis are corrected for random summing and detector efficiency. The first exponential involving the transport volume $\left(V_{t}\right)$ accounts for the probability of decay before reaching the sample volume, while the remaining factor $\left(V_{s}\right)$ accounts for the probability of decay while passing through the sample volume. This equation is valid so long as the specie involved remains entrained in the effluent gas and travels through the gas lines and sample volume at the flow rate, and the flow rate is fairly constant. Any specie trapping prior to exiting the sample volume or large variations in the flow rate during acquisition would compromise the calculation [8].

The estimated uncertainty in $R_{c}$ can thus be determined from standard error propagation techniques to be

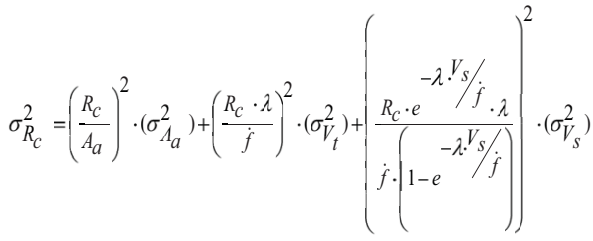

or in terms of relative errors:

$\left.\left(\frac{\sigma_{R_{c}}}{R_{c}}\right)^{2}=\left(\frac{\sigma_{A_{a}}}{A_{a}}\right)^{2}+\left(\frac{\lambda \cdot V_{t}}{\dot{f}}\right)^{2}\left(\frac{\sigma_{V_{t}}}{V_{t}}\right)^{2}+\frac{V_{s} \cdot e^{-\lambda \cdot V_{s} / \dot{f}} \cdot \lambda}{\dot{f} \cdot\left(1-e^{-\lambda \cdot V_{s} / \dot{f}}\right)}\right]^{2}\left(\frac{\sigma_{V_{s}}}{V_{s}}\right)^{2}$ 
To speed the calculation of these ratios and to ensure accuracy, a semiautomatic processing code called FP PostProc was developed. This program accesses the summary file of each spectral analysis to extract the required results for activity at the detector at a given time.

\section{III.C. Birthrate Computation}

The AGR-1 experiment capsule assembly consists of six axially-stacked capsules. Each capsule contains a graphite holder with three channels to accommodate three stacks of compacts (four compacts per stack). Each holder then accommodates 12 fuel compacts per capsule, so the entire AGR-1 experiment consists of 72 fuel compacts [9].

For the analysis, baseline fuel compacts were placed in Capsules 6 (top capsule) and 3. Variant 1 fuel compacts were placed in Capsule 5, Variant 2 fuel compacts were placed in Capsule 2 and Variant 3 fuel compacts were placed in Capsules 1 (bottom capsule) and 4. Each AGR-1 fuel compact was subdivided axially into two equal-sized cells. Thus, Stack-1 is comprised of Nodes 1-48 (eight cells per capsule times six capsules), Stack-2 is comprised of Cells 97-144, and Stack-3 is comprised of Cells 49-96 [9,10]. Fig. 4 shows the axial arrangement for two of the three compact stacks.

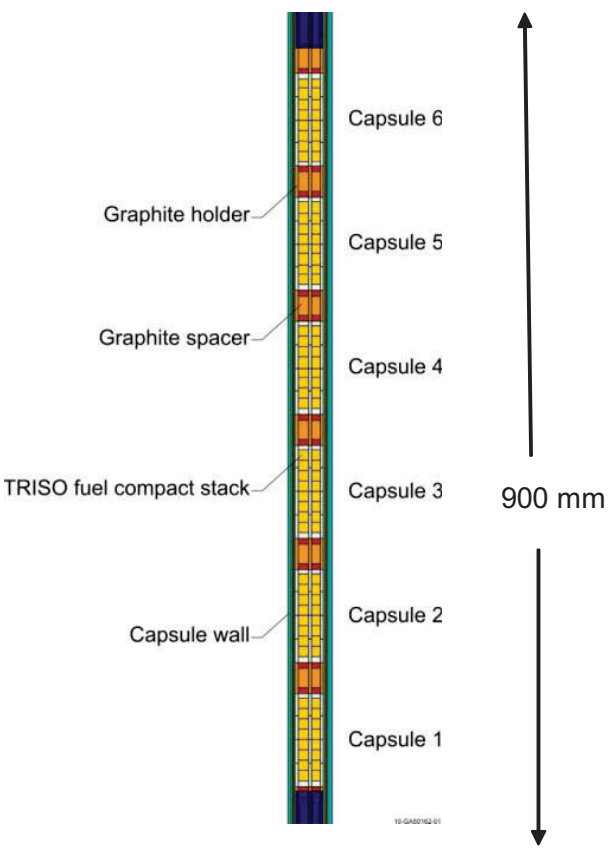

Fig. 4: Axial cross-section view of the AGR-1 experiment capsule assembly [12] as modeled in MCNP.
The original four-point isotopic birth rates (B) for the isotopes listed in Table 2 were computed from inventory data supplied using a code called MCWO (for Monte Carlo With Origen) developed at INL that linked neutronic data computed in MCNP to inventory data computed in ORIGEN2 [11]. Daily isotopic birth rates are computed from inventory data supplied using JMOUCP and ORIGEN2.2 [12]. By definition birthrate is the rate of production for a specific isotope. The birthrate is different than isotopic inventory in that production of an atom is considered to be a birth, even if it is immediately lost to transmutation or decay [9]. To calculate birthrates using ORIGEN2.2, the depletion of isotopes through transmutation and decay needs to be turned off. This was accomplished by creating decay and activation libraries for each isotope of interest. In the isotope-specific decay libraries, the half-life of the isotope was set to zero to have ORIGEN2.2 treat the isotope as a stable isotope, which turns off the decay for the isotope. In the isotope specific activation library, the absorption cross-sections were set to zero to turn off transmutation for the isotope. With decay and transmutation turned off for the specific isotope, the change in inventory for the isotope divided by the irradiation time results in the birthrate.

To couple the birthrate data with the FP_PostProc software the birthrate values for a capsule represent a volume integral over all of the compacts within the capsule and are presented in units of atoms $/ \mathrm{sec}$. The birthrate file lists values for each of the six capsules at a set number of times distributed over the irradiation cycle. The FP_PostProc software interpolates between these points to obtain estimates at the times corresponding to spectra for which the reactor is at full power.

The desired release-to-birth ratio for the desired isotope, is then calculated as:

$$
\left(\frac{R}{B}\right)(t)=\frac{R_{c}(t)}{B(t)}
$$

with a percent uncertainty $(\% \sigma)$ given by:

$$
\% \sigma=\sqrt{\left(\frac{\sigma_{R_{c}}}{R_{c}}\right)^{2}+\left(\frac{\sigma_{B}}{B}\right)^{2}} \times 100
$$




\section{RESULTS}

\section{IV.A. Differences in Birth Rates}

Originally, birthrates for the AGR-1 experiment were computed at the end of each irradiation cycle. The provided birth rates for the beginning, two middle, and end of each cycle were interpolated by the FP_PostProc to obtain birth rates for each release activity, and used to compute the fractional release or $\mathrm{R} / \mathrm{B}$. This data supplied the experiment team with information pertaining to fuel integrity during the multiyear irradiation. At the conclusion of the AGR-1 experiment, high resolution daily depletion calculations were performed [12] to provide daily compact and component heat rates for highresolution thermal analyses. The daily physics analysis also increased the number of tracked fission product isotopes in the TRISO particle compacts in order to assist in post irradiation examination measurements and to better characterize irradiated compacts.

For the AGR-1 test, the depletion time-step was changed from four time steps per interval (or 15 days per time step) to a 24-hour period (daily). Switching to a 24-hour time step enables the user to model daily changes or perturbations in core power and reactivity. The daily depletion method also generated daily reaction cross-sections for the tracked actinides and fission products and compact fission powers. These values were then used to compute the birthrate of specific fission product isotopes (Table 2) for each day of irradiation [9].The daily depletion analysis used 662 time-steps (as opposed to the four-point/interval analysis, which only used 52 steps for the entire 3-year irradiation period), thus resulting in $1,142,936$ ORIGEN2 input files for daily birth rate computation instead of the original 14,976 ORIGEN input files. Figs. 5-7 show the calculated differences in Capsule 1 birthrates for the four points per interval method versus the high resolution daily depletion method. Differences between the two computation models vary more in the beginning of the experiment, in part because the Boron-10 from the borated graphite holders at the beginning (0 EFPD) through the middle (310 EFPD) deplete rapidly and diminish as the B-10 is depleted at the end of the experiment (Cycle 145A). These figures also capture the detail of the daily birthrates as one can easily see with the resolution of the cycle power ramp-up and reactor scrams.

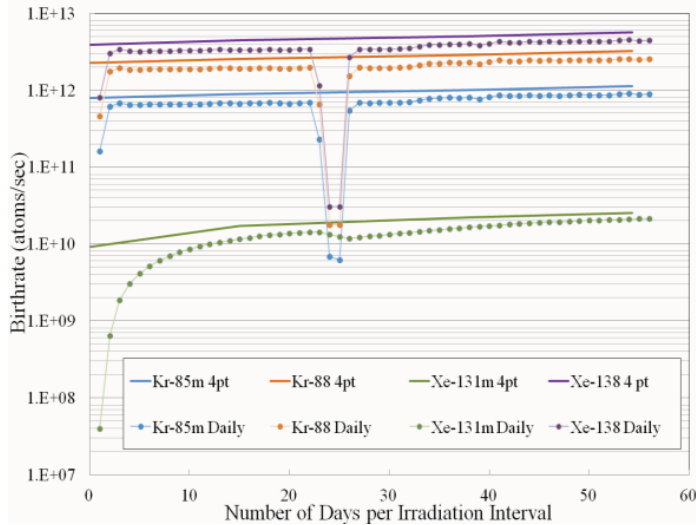

Fig. 5: Differences between four-point/interval and daily birthrates for 0 EFPD (irradiation interval-2) of AGR-1 Capsule 1.

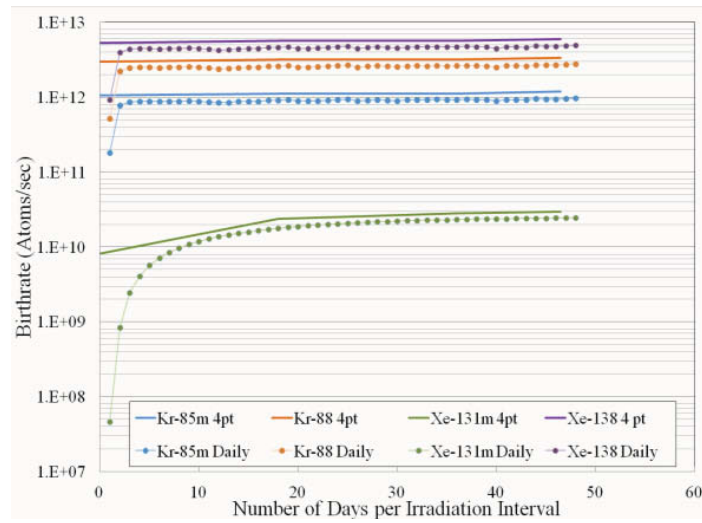

Fig. 6: Differences between four-point/interval and daily birthrates for 310 EFPD (irradiation interval-4) of AGR-1 Capsule 1.

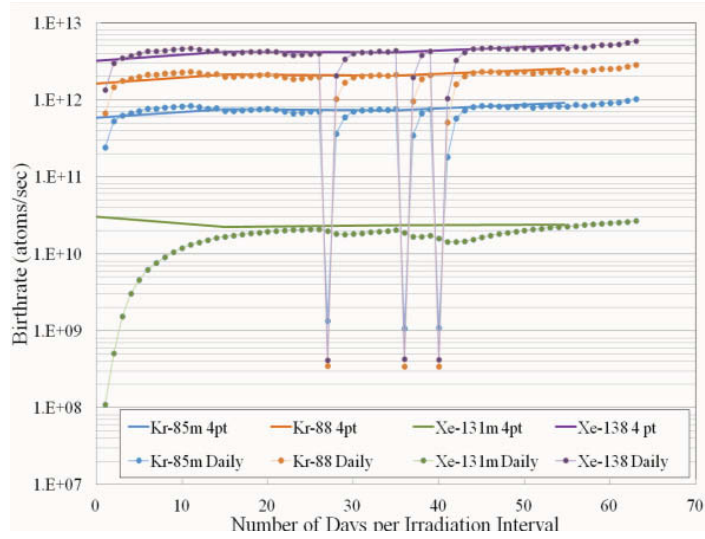

Fig. 7: Differences between four-point/interval and daily birthrates for 620 EFPD (irradiation interval13) of AGR-1 Capsule 1. 
Since AGR-1 was a multicapsule experiment, the percent difference between the four-point and daily birth rates are presented in Table 3, which shows the daily birthrates for the entire AGR-1 experiment averaging 13\% lower than the original four-point birthrates. Capsule 6 has an overall higher percent difference because of methodology resolution and proximity of this capsule to the high worth ATR hafnium safety rods positioned at the top of the active core.

\begin{tabular}{lc}
\hline AGR-1 Birthrate Percent Difference \\
\hline Capsule 1 & 14 \\
Capsule 2 & 11 \\
Capsule 3 & 10 \\
Capsule 4 & 11 \\
Capsule 5 & 14 \\
Capsule 6 & 18 \\
\hline
\end{tabular}

Table 3: AGR-1 birthrate percent difference capturing the variation between four-point and daily birthrate values.

\section{IV.B. Daily Release to Birth Ratio Data}

Over the course of the AGR-1 experiment, spectrometer data acquired on AGR-1 were routinely examined for evidence of irradiation test-induced TRISO fuel particle failures. By November 2009, the test fuels exceeded peak burnups of 19\% FIMA in three of the six capsules with a minimum peak of $15 \%$ FIMA with no evidence of a particle failure [2]. Based on the spectrometer data, all measured releases are consistent with and assumed to come from heavy metal contamination in the fuel. Reprocessing of the $\mathrm{R} / \mathrm{B}$ with the daily birthrates yielded slightly higher ratios but did not have an overall impact on the original conclusion. Once again the measured $\mathrm{R} / \mathrm{B}$ values indicated excellent fuel performance when compared to both historical U.S. TRISO fuel experience [13] and modern German TRISO fuel tests [14]. Figs. 8-13 show averaged AGR-1 R/B relative to isotopic half lives. Data from the first irradiation cycle starting on December 24, 2006, is not included in Figs. 5-10 because the experiment was undergoing initial experiment shakedown testing. Figs. 14-16 capture the difference between high resolution daily method and 4 point $\mathrm{R} / \mathrm{Bs}$ for $\mathrm{Kr}-85 \mathrm{~m}$. The differences between the two data sets are attributed primarily to the increased resolution with the daily birth rate calculations. Variations in the R/B's were primarily caused by experiment gas mixtures, variances in gas flow rates and temperature effects. The variances are observed in Figs. 14-16 by the cyclic nature of the plots. Reactor shutdowns are also represented in Figs. $17-19$ by voids in the data set.
The AGR-1 TRISO particle fuel experiment underwent 13 irradiation intervals at the ATR from December 2006 to November 2009 in support of the Next Generation Nuclear Plant (NGNP) program. During this multiyear experiment, R/Bs were computed at the end of each operating interval to provide information relative to fuel performance.

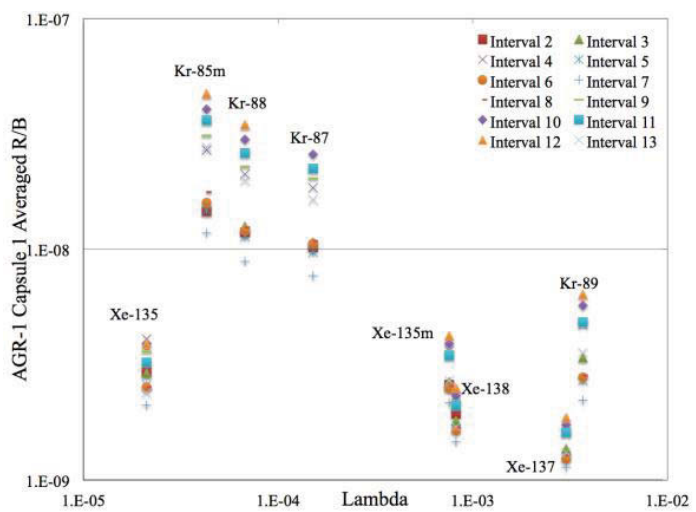

Fig. 8: Capsule 1 averaged R/B for the AGR-1 experiment.

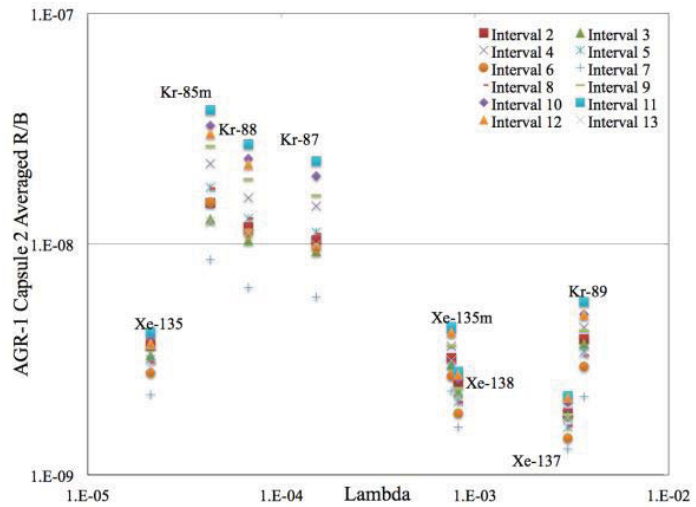

Fig. 9: Capsule 2 averaged R/B for the AGR-1 experiment. 


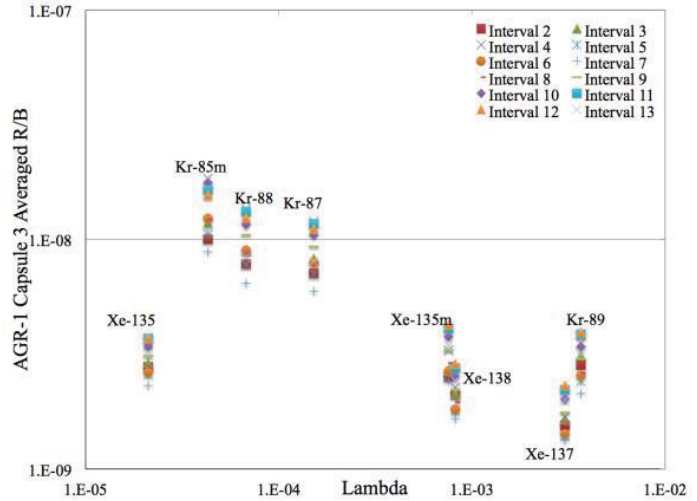

Fig. 10: Capsule 3 averaged R/B for the AGR-1 experiment.

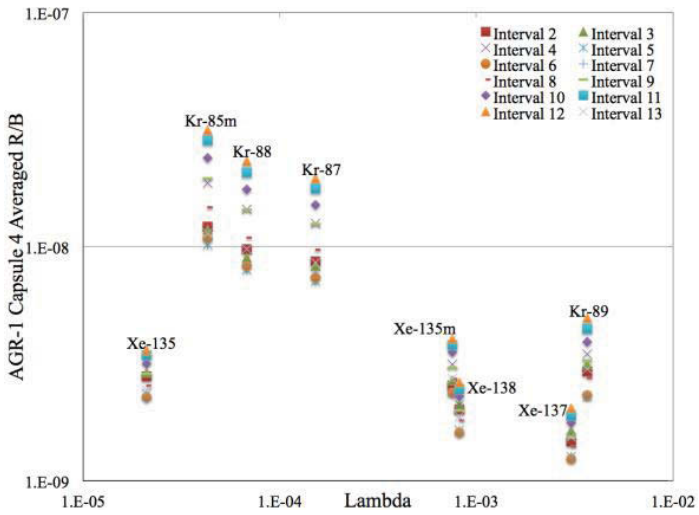

Fig. 11: Capsule 4 averaged R/B for the AGR-1 experiment.

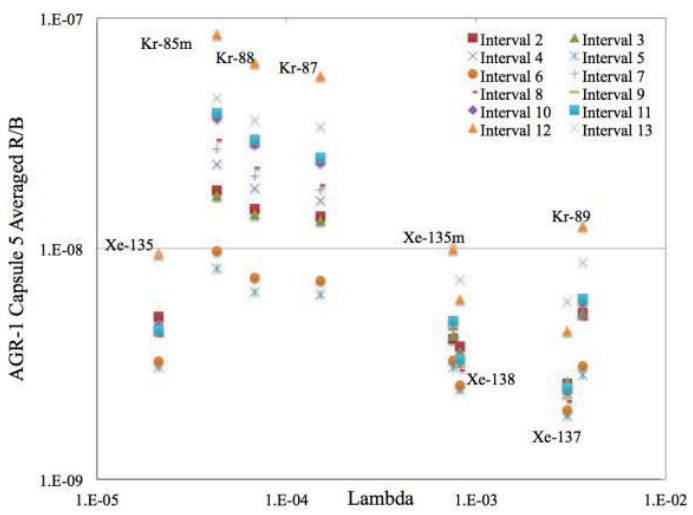

Fig. 12: Capsule 5 averaged R/B for the AGR-1 experiment.

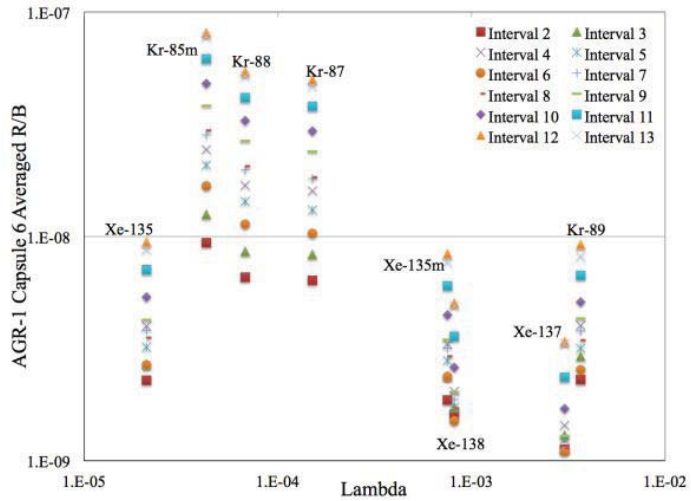

Fig. 13: Capsule 6 averaged R/B for the AGR-1 experiment.

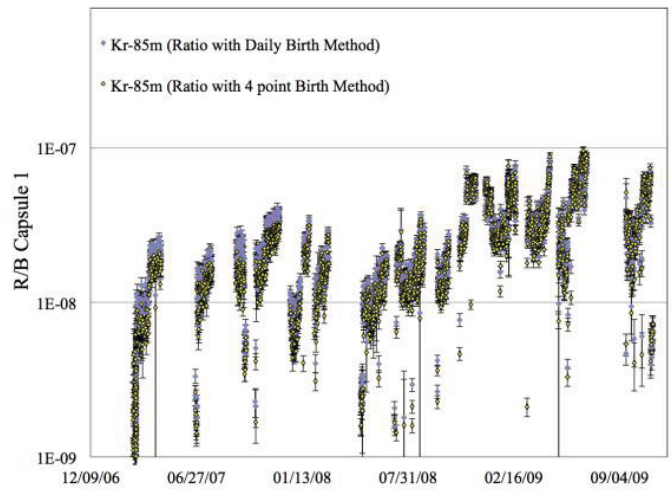

Fig. 14: Capsule $1 \mathrm{R} / \mathrm{B}$ for $\mathrm{Kr}-85 \mathrm{~m}$ capturing the difference between the computed daily and 4-point $\mathrm{R} / \mathrm{B}$.

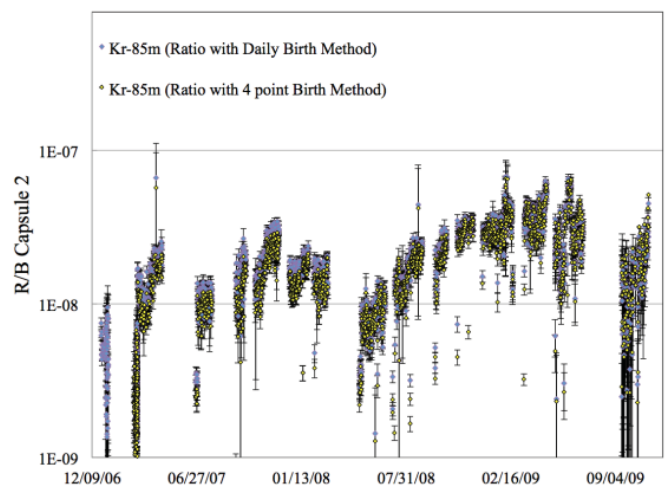

Fig. 15: Capsule $2 \mathrm{R} / \mathrm{B}$ for $\mathrm{Kr}-85 \mathrm{~m}$, capturing the difference between the computed daily and 4-point $\mathrm{R} / \mathrm{B}$ ratio. 


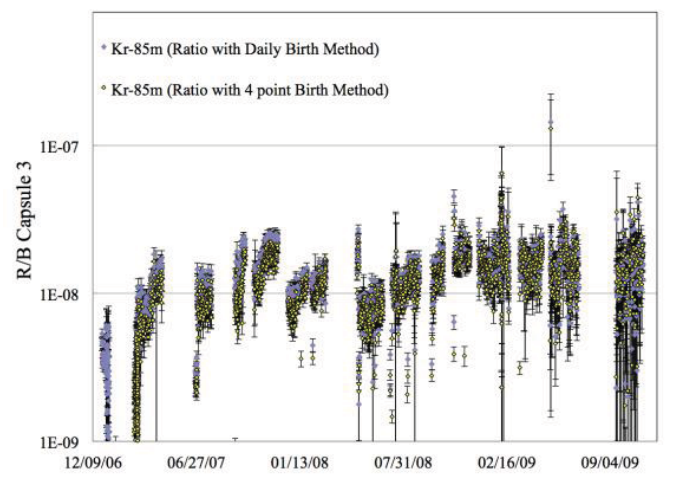

Fig. 16: Capsule $3 \mathrm{R} / \mathrm{B}$ for $\mathrm{Kr}-85 \mathrm{~m}$ capturing the difference between the computed daily and 4-point $\mathrm{R} / \mathrm{B}$ ratio.

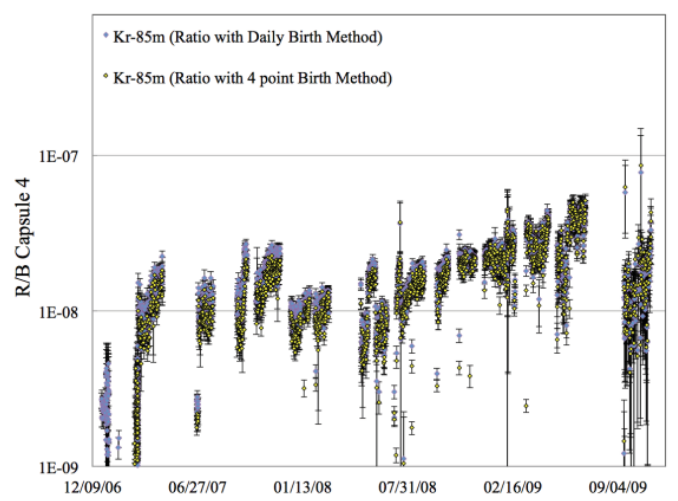

Fig. 17: Capsule $4 \mathrm{R} / \mathrm{B}$ for $\mathrm{Kr}-85 \mathrm{~m}$ capturing the difference between the computed daily and 4-point $\mathrm{R} / \mathrm{B}$ ratio.

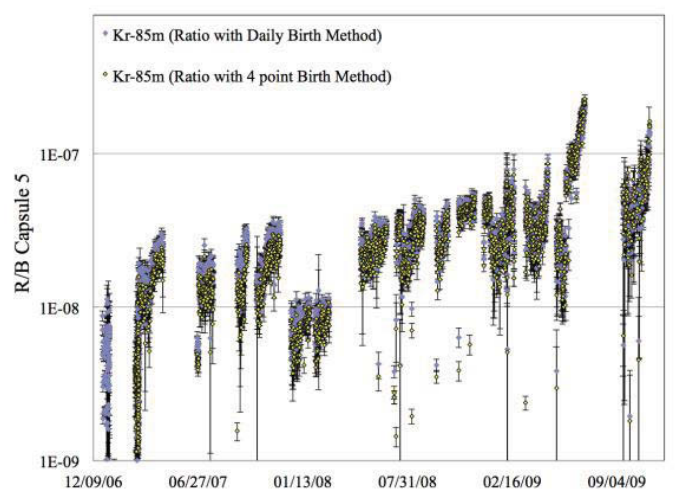

Fig. 18: Capsule $5 \mathrm{R} / \mathrm{B}$ for $\mathrm{Kr}-85 \mathrm{~m}$ capturing the difference between the computed daily and 4-point $\mathrm{R} / \mathrm{B}$ ratio.

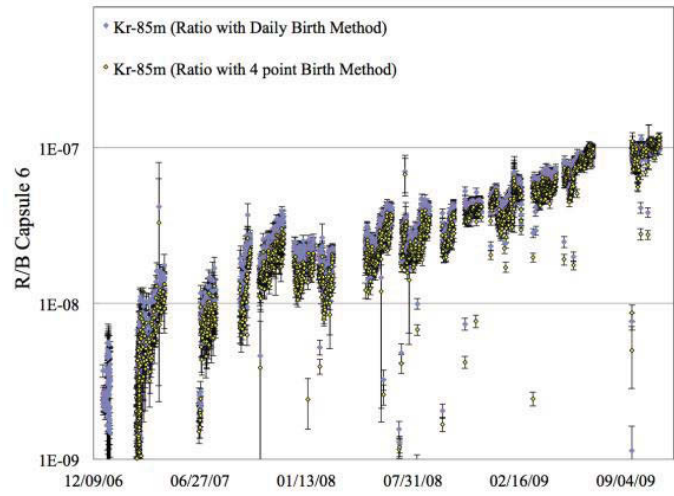

Fig. 19: Capsule 6 Release to Birth Ratio for Kr-85m capturing the difference between the computed daily and 4-point $\mathrm{R} / \mathrm{B}$ ratio.

\section{CONCLUSION}

Fission product release rates were measured during irradiation 3 times daily by the INL Fission Product Monitoring System (FPMS) using eight (8) hour measurements. Birth rates were calculated by MCNP with ORIGEN for as-run conditions at the end of each irradiation time-step during an ATR power interval.

Release-to-birthrate ratios (R/B) were computed to each calculational time step. Two similar MCNP/ORIGEN methods were used to compute the $\mathrm{R} / \mathrm{B}$ ratios but with different time resolutions. The high resolution method calculated birthrates on a daily basis and took into account the daily core power fluctuations and shim control surface movements. R/B ratios computed with the highresolution daily method produced slightly higher $\mathrm{R} / \mathrm{B}$ ratios which are believed to be more accurate. Overall the R/B ratios indicated excellent TRISO particle fuel performance with no fuel failures for the baseline and variant particles.

\section{REFERENCES}

[1] C.M. Barnes, "AGR-1 Fuel Product Specification and Characterization Guidance," EDF-4380, Idaho National Laboratory, April 21, 2006.

[2] S.B. Grover, "Completion of the First NGNP Advanced Gas Reactor Fuel Irradiation Experiment, AGR-1, in the Advanced Test Reactor," Paper \#104, Proceedings HTR-2010, Prague, Czech Republic, October 18-20, 2010.

[3] D.M. Scates, "Fission Product Monitoring and Release Data for the Advanced Gas Reactor -1 Experiment," Paper \#52, Proceedings HTR- 
2010, Prague, Czech Republic, October 18-20, 2010.

[4] D.M. Scates, "User's Guide for the Fission Product Monitoring System," GDE-503, Idaho National Laboratory, April 16, 2009.

[5] E.W. Killian and L.V. East, "PCGAP: Application to analyze gamma-ray pulse-height spectra on a personal computer under Window NTC," J. Radioanalytical Nucl. Chem., Vol. 233, No. 1-2, pp. 109-114, 1998.

[6] E.W. Killian and J.K. Hartwell "PCGAP: Users Guide and Algorithm Description," Idaho National Engineering and Environmental Laboratory Report INEEL/EXT-2000-00908, Sept. 2000.

[7] J.K. Hartwell, et al., "Determination of the AGR-1 Capsule to FPMS Spectrometer Transport Volumes from Leadout Flow Test Data," INL/EXT-07-12494, May 2007.

[8] D.M. Scates, "Release-to-Birth Ratios for AGR-1 Operating Cycles 138B through 145A," ECAR-907, Rev-1, Idaho National Laboratory, July 9, 2012.

[9] J.R Parry, "AGR-1 Daily Birthrate Analysis," ECAR-1710, Idaho National Laboratory, February 15, 2012.
[10] C.M. Barnes, "AGR-1 Fuel Product Specification and Characterization Guidance," EDF-4380, Rev-8, Idaho National Laboratory, April 21, 2006.

[11] G. Chang, "MCWO - Linking MCNP and ORIGEN2 for Fuel Burnup Analysis," Proceedings of the 2005 ANS Topical Meeting Monte Carlo 2005, Chattanooga, TN, April 1721, 2005.

[12] J.W. Sterbentz, "JMOCUP As-Run Daily Depletion Calculation for the AGR-1 Experiment in ATR B-10 Position," ECAR-958, Idaho National Laboratory, August 18, 2011.

[13] D.A. Petti, J. Buongiorno, J.T. Maki, R.R. Hobbins, G.K. Miller, "Key differences in the fabrication, irradiation, and high temperature accident testing of US and German TRISO-coated particle fuel, and their implications on fuel performance," Nuclear Engineering and Design, v. 222, i. 2-3, (2003)

[14] Verfondern, K. (Ed.), "Fuel Performance and Fission Product Behaviour in Gas Cooled Reactors," IAEA TECDOC-978, International Atomic Energy Agency, (1997). 